\title{
Self and partner satisfaction rates after 3 part inflatable penile prosthesis implantation
}

\author{
Abdulmuttalip Simsek, Onur Kucuktopcu, Faruk Ozgor, Unsal Ozkuvanci, Murat Baykal, \\ Omer Sarilar, Zafer Gokhan Gurbuz \\ Haseki Research and Training Hospital, Department of Urology, Turkey.
}

\begin{abstract}
Summary Objective: To evaluate and present satisfaction rates of our patients and their partners after 3 part inflatable penile prosthesis implantation.

Materials and methods: We searched our hospital electronic data for patients who underwent inflatable penile prosthesis implantation between January 2008 and July 2013. Computer and archived file data were used to get information and reach the patients. We made telephone calls to patients and asked questionnaires about self and partner satisfaction rates.

Results: 36 patients underwent prosthesis implantation during the 5 year period. We were able to reach by telephone call 18 of them. The mean age of 18 patients was $55.7 \pm 9.4$ years and mean body mass index was $24.6 \pm 2.1 \mathrm{~kg} / \mathrm{m}^{2}$. The etiology was diabetes mellitus on $14(77.8 \%)$ and radical pelvic surgery on 4 (22.2\%) patients. 14 of 18 patients had penile Doppler ultrasound test. Doppler ultrasound demonstrated venous insufficiency in 8 and arterial insufficiency in 6 patients. Mean time from implantation to study was $20.8 \pm 13.9$ months.
\end{abstract} Out of 18 patients 2 had prosthesis removal operation because of infection in one patient and perforation in the other. Satisfaction rate was $88.9 \%$, and recommendation rate was $94.4 \%$. Causes of dissatisfaction were pain in one patient and insufficient rigidity plus shortening of the penis in the other one. Partner satisfaction rate was $94.4 \%$.

Conclusion: Penile Prosthesis Implantation (PPI) is the gold standard treatment of erectile dysfunction (ED) irresponsive to medical treatment. Infection and mechanical failure rates are going to be less according to the improvements in synthetic materials and coverings of the prosthesis, so patient and partner satisfaction rates will be higher.

KEY WORDS: Penile prosthesis; Erectile dysfunction;

Satisfaction rate.

Submitted 30 June 2014; Accepted 1 August 2014

\section{INTRODUCTION}

Erectile dysfunction (ED) affects more than half of men between 40 and 70 years of age. Oral phosphodiesterase type-5 inhibitors and intracavernosal injections (ICI) are first and second line therapies respectively. Penile vascular surgery is indicated for healthy men with acquired ED due to isolated stenosis of extra penile arteries without any kind of generalized vascular disease (1).

Phosphodiesterase type 5 inhibitors will fail in approximately $25-30 \%$ of patients and they will therefore be offered intracavernosal injection. Since most patients drop out ICI treatment, around 10-15\% of patients with ED will be candidate for penile prosthesis implantation (PPI) (2).

Prosthetic implants for ED have been used successfully for many years. Scott et al in 1973 introduced the inflatable penile prosthesis (IPP) and initiated the modern treatment of erectile dysfunction (3). 5-year survival rate is greater than $90 \%$ and more than $90 \%$ of patients are satisfied with the function of their prosthesis (4).

In this retrospective study using a non-validated questionnaire, we aimed to evaluate the satisfaction rates of the patients and their partners, reasons of unsatisfaction and need for sexual partner change.

\section{Materials AND Methods}

Between January 2008 and July 2013, three part IPP implantation was performed in 36 patients. Patient data was obtained by searching of computer data base of our hospital and archived files of the patients. Computer data base is searched for the term of "penile prosthesis". So we could find the patients who underwent penile prosthesis implantation or penile prosthesis removal. Patients data were evaluated for the etiologies and for prosthesis removal in the same hospital or not. All patients were interviewed by phone using number which were recorded in the archived files or in the computer data base. If we could reach the patients by the recorded telephone number we asked several questions to evaluate the use of prosthesis. The questions are shown in Table 1 (Supplementary Materials). Patient and partner satisfaction rates, co morbidities, etiology of ED, penile Doppler ultrasound results, time between start of complaints and implantation, prosthesis failure rates and causes, and need for partner change were evaluated. All the parameters were evaluated as means, standard deviations, percentages and number of patients. 


\section{RESULTS}

Between January 2008 and July 2013, we implanted three-part IPP to 36 patients depending on computer database search results. According to the data from computer and archived files of patients, the etiology of erectile dysfunction was diabetes mellitus in 18, priapism in 1 , radical pelvic surgery in 9 and unknown in 8 patients. Of these 36 patients 4 were recorded for removal of prosthesis. The cause of prosthesis removal was infection in 3 patients and perforation in 1 patient.

Out of 36 patients recorded on computer, we could reach only 18 patients by telephone. All of them answered our questionnaire. The mean age of 18 patients was $55.7 \pm 9.4$ years and mean body mass index was $24.6 \pm 2.1 \mathrm{~kg} / \mathrm{m}^{2}$. The etiology was diabetes mellitus in 14 (77.8\%) and radical pelvic surgery in 4 (22.2\%). Fourteen of 18 patients had penile Doppler ultrasound test which demonstrated venous insufficiency in 8 and arterial insufficiency in 6 patients. The patients suffered from erectile dysfunction from a mean of $4 \pm 3$ years. Mean time from implantation to study was $20.8 \pm 13.9$ months. Patients used their prosthesis on a mean of $8 \pm 3.1$ times per month. Of these 18 patients 2 had prosthesis removal operation because of infection in one case and perforation in another case. Sixteen $(88.9 \%)$ patients were satisfied with their prosthesis and 2 (11.1\%) were dissatisfied. Causes of dissatisfaction were pain in one patient and insufficient rigidity and shortening of penis in the other one. Surprisingly 5 patients reported shortening of penis but 4 of them did not complain about and only one of them was dissatisfied because of shortening. None of them reported cosmetic problems and none of the patients needed to change their sexual partners after implantation. Patients reported 17/18 (94.4\%) partner satisfaction rate. But the unsatisfaction cause of this one partner was urinary incontinence of the male because of radical prostatectomy rather than the erection status. Only one patient that was dissatisfied because of insufficient rigidity and penile length reported that he could not recommend the implantation. The recommendation rate was $94.4 \%$.

\section{Discussion}

PPI surgery is the treatment method in patients with end stage ED when oral and ICI treatments are ineffective or contraindicated (5). Arterial and venous dysfunctions caused by systemic diseases (6) or non nerve sparing surgery on bladder, prostate or rectum can cause ED needing prosthesis implantation $(7,8)$.

Inflatable devices have been initially introduced by Scott in 1973 (3) and now are available in a two and three pieces version. IPP can be deflated mimicking the flaccid penile state. They are associated with higher patient and partner satisfaction rates than malleable prosthesis as they allow expansion of penis, thus preventing the risk of "pencil penis" syndrome and cosmetic problems (9). None of our patients in this study reported occurrence of such cosmetic problems after implantation.

Reliability of the device has been significantly improved and mechanical failure rates declined from 61\% to $10-$ $20 \%$ at approximately $5-10$ years of follow up (10). If the failure occurs in the early months, it is not necessary to remove the entire device and the identification and exchange of the faulty component usually suffices. If the mechanical failure occurs after 2 years instead, it is advisable to exchange the entire device (9). In this study prosthesis removal surgery was done for $2(6 \%)$ patients in the total group of 36 patients and for one $(6 \%)$ patient out of 18 patients interviewed by phone because of perforation of prosthesis.

Infection ranges from $1.8 \%$ to $10 \%$ and is an important complication which could cause the revision or the removal of the device (11). Infections are generally caused by Staphylococcus epidermidis and S. aureus, followed by Gram-negative bacteria and anaerobic organisms (12). In our study infection rates was $6 \%$ for both the total group and the group of interviewed patients.

Patients who have already undergone this kind of treatment defined really high rates of satisfaction, up to $97 \%$ of cases $(9,13)$. Satisfaction rates are better assessed with the use of validated questionnaires such as the International Index of Erectile Function (IIEF) and the Erectile Dysfunction Inventory of Treatment Satisfaction (EDITS)(14-15). The EDITS questionnaire was first validated in 1999 as an instrument by which patients' and partners' satisfaction with treatments for erectile dysfunction could be assessed (15).

Satisfaction can be affected by many variables. Partner behavior plays a role (16) and patient expectations can have a great impact (17). Satisfied patients have favorable partner sexual function compared to that of unsatisfied patients. The correlation observed suggests that patients not satisfied with their inflatable penile prosthesis (IPP) are likely to have female partners at high risk for female satisfaction. Also female satisfaction rate correlates satisfaction rates of the patients. Studies suggested a direct linear correlation of satisfaction between the sexual partners (16).

Also in our study, patient and partner satisfaction rates were $88.9 \%$ and $94.4 \%$ respectively, similarly to the literature. None of our patients defined dissatisfaction due to bad partner sexual performance and none of them needed to change their partners.

Of the $8 \%$ who were unsatisfied in the Bettocchi et al. paper, the main reasons given were insufficient rigidity and penile length (9).

Moreover, the same could be said for the Garber's study where $8 \%$ were dissatisfied with penile length. One of our patients dissatisfied because of pain, and one patient (5.6\%) was dissatisfied because of insufficient rigidity and shortening of the penis. Five patients (27.8\%) had shortening problem but only one of them was dissatisfied.

One limitation in this study is that we did not use validated questionnaires for evaluating the satisfaction of patients and partners. We asked only if the patient was satisfied and if he recommended this treatment to another patient or not. According to our questionnaire our satisfaction rate was $88.9 \%$ and this was compatible with the literature. Seventeen (94.4\%) patients recommended PPI treatment. One patient who was dissatisfied because of pain also recommended this treatment because of good rigidity of penis.

Another limitation of our study was a low patient number. Bettocchi et al. studied 79 patients between 2004-2008. In 
their study $92 \%$ of patients defined improvement in sex and $97 \%$ would recommend the same surgery to others (9). Montorsi et al. studied 200 patients between 19861997 and 92\% patients had satisfactory sexual activity (18). Goldstein et al. studied 234 patients between 19891993 and $86 \%$ of patients recommended surgery to others (19). Our results correlate with rate reported on literature.

\section{Conclusion}

Today, PPI is the gold standard treatment of ED irresponsive to medical treatment. Patient and partner satisfaction rates are high. Infection and mechanical failure rates are going to be less according to the improvements in synthetic materials and coverings of prosthesis. More studies about factors effecting dissatisfaction after surgery, especially about female factors resulting in partner changes, should be done.

\section{REFERENCES}

1.Montague DK, Jarow JP, Broderick GA, et al. Erectile dysfunction guideline update panel. Chapter I: The management of erectile dysfunction: an AUA update. J Urol. 2005; 174:230-239.

2. Montague DK. Penile prosthesis implantation in the era of medical treatment for erectile dysfunction. Urol Clin North Am. 2011; 38:217-25.

3. Scott FB, Bradley WE, Timm GW. Management of erectile impotence: use of implantable inflatable prosthesis. Urology. 1973; 2:80.

4. Carson CC, Mulcahy JJ, Govier FE. Efficacy, safety, and patient satisfaction outcomes of an AMS 700 CX inflatable penile prosthesis: results of a long term multicenter study. J Urol. 2000; 164:376-382.

5. Montorsi F, Deho F, Salonia A, et al. Penile implants in the era of oral drug treatment for erectile dysfunction. BJU Int. 2004; 94:745-51.

6. Hatzimouratidis K, Hatzichristou DG. Treatment options for erectile dysfunction in patientsfailing oral drug therapy. EAU Updates Series. 2004; 2:75.
7. Meuleman EJ, Mulders PF. Erectile function after radical prostatectomy: a review. Eur Urol. 2003; 43:95-101.

8. Bettocchi C, Palumbo F, Spilotros M, et al. Penile prostheses. Ther Adv Urol. 2010; 2:35-40.

9. Bettocchi C, Palumbo F, Spilotros M, et al. Long term patient satisfaction and quality of life with AMS700CX inflatable penile prosthesis. J Sex Med. 2010; 7:304-9.

10. Kim SC Mechanical reliability of AMS hydraulic penile prostheses. J Korean Med Sci. 1995; 10:422-425.

11. Al-Enezi A, Al-Khadhari S, Al-Shaiji TF. Three-piece inflatable penile prosthesis: surgical techniques and pitfalls. J Surg Tech Case Rep. 2011; 3:76-83

12. Evans $C$. The use of penile prostheses in the treatment of impotence. BJU. 2001; 81:591-598.

13. Natali A, Olianas R, Fisch M. Penile implantation in Europe: successes and complications with 253 implants in Italy and Germany. J Sex Med. 2008; 5:1503-1512.

14. Mulhall JP, Ahmed A, Branch J, Parker M. Serial assessment of efficacy and satisfaction profiles following penile prosthesis surgery. J Urol. 2003; 169:1429-1433.

15. Althof SE, Corty EW, Levine SB, et al. EDITS: development of questionnaires for evaluating satisfaction with treatments for erectile dysfunction. Urology. 1999; 53:793-9.

16. Gittens P, Moskovic DJ, Avila D Jr, et al. Favorable female sexual function is associated with patient satisfaction after inflatable penile prosthesis implantation. J Sex Med. 2008; 8:1996-2001.

17. Kramer AC, Schweber A. Patient expectations prior to coloplast titan penile prosthesis implant predicts postoperative satisfaction, $J$ Sex Med. 2010; 7:2261-2266.

18. Montorsi F, Rigatti P, Carmignani G, et al. AMS three-piece inflatable implants for erectile dysfunction: a long-term multi institutional study in 200 consecutive patients. Eur Urol. 2000; 37:50-55.

19. Goldstein I, Newman L, Baum, et al. Safety and efficacy outcome of mentor alpha-1 inflatable penile prosthesis implantation for impotence treatment. J Urol, 1997; 157:833-839.

\section{Correspondence}

Abdulmuttalip Simsek, MD (Corresponding Author)

simsek76@yahoo.com

Onur Kucuktopcu, MD

Faruk Ozgor, MD

Unsal Ozkuvanci, MD

Murat Baykal, MD

Omer Sarilar, MD

Zafer Gokhan Gurbuz, MD

Haseki Training and Research Hospital,Department of Urology,

Millet Cad. No: 11, 34000 Fatih, Istanbul, Turkey 